\title{
PERBAIKAN PROSES PRODUKSI DAN KUALITAS PRODUK KEMBANG GOYANG DI UMKM IBU SUPIYAH
}

\author{
Andry M. Panjaitan ${ }^{1}$, Rudy V. Silalahi ${ }^{1}$ Franco P. Putra ${ }^{1}$ \\ ${ }^{1}$ Universitas Pelita Harapan \\ andry.panjaitan@uph.edu, rudy.silalahi@uph.edu, francoadzan@gmail.com
}

\begin{abstract}
Abstrak
UMKM merupakan salah satu penggerak ekonomi di Indonesia, dimana 60\% dari PDB berasal dari UMKM. Pengabdian Kepada Masyarakat ini dilakukan di UMKM Ibu Supiyah, yang terletak di Kranggan, Tangerang. UMKM Ibu Supiyah adalah salah satu UMKM yang menjual aneka ragam cemilan. Dalam UMKM tersebut, ditemukan bahwa kembang goyang memiliki tingkat kegurihan dan warna yang berbeda. Selain itu, proses produksi masih bersifat tradisional. Oleh karena itu, dilakukan upaya untuk meningkatkan konsistensi gurih dan warna dari kembang goyang dan menurunkan waktu siklus dari proses produksi melalui perancangan dan penerapan Standard Operating Procedure (SOP). Data didapatkan melalui wawancara dan pengamatan langsung ke UMKM Ibu Supiyah. Analisa konsistensi dari kembang goyang diukur menggunakan alat ukur Texture Analyzer untuk mengukur tingkat Hardness dan Chroma Meter untuk mengukur tingkat Lightness. Setelah SOP sudah diterapkan dalam UMKM Ibu Supiyah, diketahui bahwa persentase standar deviasi Hardness kembang goyang berkurang sebesar $8,6 \%$ dari $23,8 \%$ menjadi 15,2\%. Selain itu, persentase standar deviasi lightness berkurang sebesar 1,56\% dari 8,58\% menjadi 7,02\%. Perubahan dari penerapan SOP juga dapat dilihat secara jelas secara visual bahwa warna kembang goyang sudah lebih konsisten dari sebelum diterapkannya SOP. Melalui tabel Value Stream Mapping (VSM), dapat dilihat bahwa waktu siklus yang digunakan berkurang sebesar 680 detik dari 3485 detik menjadi 2805 detik.
\end{abstract}

Kata Kunci : SOP, proses produksi, VSM.

\section{PENDAHULUAN}

UMKM Ibu Supiyah adalah salah satu usaha di Desa Kranggan, berupa menjual dan memproduksi makanan ringan tradisional. Makanan yang diproduksi atau dijual adalah kembang goyang, akar kelapa, dan banyak lagi. Usaha yang dikelola oleh Ibu Supiyah masih bersifat tradisional dan make-toorder. Ibu Supiyah memiliki tiga karyawan tetap, setiap karyawan bertanggung jawab atas satu lini produksi. Dengan SDM tetap, produksi per hari dapat mencapai 68 bungkus.

Karena UMKM Ibu Supiyah masih bersifat tradisional, maka masih memiliki banyak potensi agar proses produksi dIbuat menjadi lebih efisien. Saat dilakukan kunjungan awal, ditemukan bahwa warna dari kembang goyang tidak konsisten.
Terdapat juga beberapa komplain dari pembeli bahwa rasa kembang goyang tidak konsisten. Pengabdian kepada masyarakat ini bertujuan untuk merancang SOP proses produksi kembang goyang. Dengan harapan kualitas produk kembang goyang lebih konsisten dan waktu siklus produksi dapat lebih singkat.

\section{METODE}

Pada pengabdian kepada masyarakat ini tahapan yang dilakukan adalah dimulai dengan studi pendahuluan yaitu melakukan peninjauan langsung ke lokasi usaha Ibu Supiyah yang terletak di Desa Keranggan, Tangerang Selatan. Studi pendahuluan ini bertujuan untuk mengetahui secara umum keadaan dari UMKM Ibu Supiyah. Setelah dilakukan

$$
\text { Teknologi Tepat Guna }
$$


peninjauan langsung ke lokasi maka dapat dilakukan identifikasi masalah. Pada tahap ini seluruh data dan informasi mengenai UMKM Ibu Supiyah dikumpulkan dan dilihat secara teliti, untuk menentukan masalah yang perlu diselesaikan. Melalui observasi yang dilakukan, diketahui bahwa kembang goyang tidak memiliki warna yang konsisten. Pembeli juga komplain bahwa tingkat kegurihan kembang goyang tidak standar. UMKM Ibu Supiyah masih menggunakan proses produksi secara tradisional, oleh sebab itu, dapat diketahui masalah UMKM Ibu Supiyah adalah kembang goyang yang memiliki warna dan tingkat kegurihan yang tidak konsisten serta bagaimana dapat mengurangi waktu siklus. Jadi tujuan dari pengabdian masyarakat ini adalah untuk merancang SOP proses produksi kembang goyang. Dengan harapan kembang goyang menjadi lebih konsisten dan produksi dapat menurunkan waktu siklus produksi. Untuk dapat mencapai tujuan dari pengabdian masyarakat ini maka sebelumnya dilakukan kajian literatur berupa buku, jurnal yang ditulis oleh ahli, artikel dan data dari internet (seperti website Badan Pusat Statistika). Selanjutnya dilakukan pengumpulan dan pengolahan data. Data umum yang dikumpulkan berupa sejarah usaha, jadwal operasional, jumlah karyawan, proses produksi dan produk yang dijual. Data khusus berupa tingkat hardness, tingkat lightness, waktu siklus dan takaran bahan. Melalui VSM, waktu siklus dari kembang goyang dapat diketahui. Sebelum SOP dikerjakan, kembang goyang harus diuji terlebih dahulu. Dalam pengujian, alat yang digunakan adalah Texture Analyzer dan Chroma Meter yang berada di laboratorium quality control Program Studi Teknologi Pangan Universitas Pelita Harapan. Tahap selanjutnya adalah melakukan analisis dan pembahasan yang terdiri dari analisis untuk menentukan SOP yang dirancang, hasil produk setelah SOP sudah diterapkan, dan VSM setelah SOP tealh diterapkan. SOP hanya diterapkan dalam tahap pengadukan adonan dan penggorengan saja. Kembang goyang setelah SOP diterapkan akan sekali lagi diuji menggunakan Texture Analyzer dan
Chroma Meter. Tahap terakhir yang dilakukan adalah penarikan kesimpulan dari analisis dan pembahasan yang sudah dilakukan untuk menjawab tujuan pengabdian kepada masyarakat.

\section{HASIL DAN PEMBAHASAN}

\section{A. Sebelum Penerapan SOP}

Sebelum pengujian untuk kembang goyang dilakukan, time study dilakukan terlebih dahulu untuk mengetahui kapasitas produksi kembang goyang. UMKM Ibu Supiyah beroperasi dari jam 7 pagi hingga jam 12 siang. Untuk menghitung waktu baku produksi kembang goyang menggunakan formula:

Normal time $=$ observe time $\times \frac{\text { rating in percent }}{100}$

Nilai rating didapatkan dari tabel allowance westinghouse yang dapat dilihat di tabel 1 .

Tabel 1. Westinghouse Allowance Rating

\begin{tabular}{|l|l|l|l|l|l|}
\hline Skill ratings & & & $\begin{array}{l}\text { Environmental condition } \\
\text { Ratings }\end{array}$ & & \\
\hline+0.15 & A1 & Superskill & +0.06 & A & Ideal \\
\hline+0.13 & A2 & Superskill & +0.04 & B & Excellent \\
\hline+0.11 & B1 & Excellent & +0.02 & C & Good \\
\hline+0.08 & B2 & Excellent & 0.00 & D & Average \\
\hline+0.06 & C1 & Good & -0.03 & E & Fair \\
\hline+0.03 & C2 & Good & -0.07 & F & Poor \\
\hline 0.00 & D & Average & Consistency ratings & & \\
\hline-0.05 & E1 & Fair & +0.04 & A & Perfect \\
\hline-0.10 & E2 & Fair & +0.03 & B & Excellent \\
\hline-0.16 & F1 & Poor & +0.01 & C & Good \\
\hline-0.22 & F2 & Poor & 0.00 & D & Average \\
\hline Effort ratings & & & -0.02 & E & Fair \\
\hline+0.13 & A1 & Excessive & -0.04 & F & Poor \\
\hline+0.12 & A2 & Excessive & & & \\
\hline+0.10 & B1 & Excellent & & & \\
\hline+0.08 & B2 & Excellent & & & \\
\hline+0.05 & C1 & Good & & & \\
\hline+0.02 & C2 & Good & & & \\
\hline 0.00 & D & Average & & & \\
\hline-0.04 & E1 & Fair & & & \\
\hline-0.08 & E2 & Fair & & & \\
\hline-0.12 & F1 & Poor & & & \\
\hline-0.17 & F2 & Poor & & & \\
\hline & & & & & \\
\hline
\end{tabular}

Setelah nilai rating sudah ditentukan dan waktu normal sudah didapatkan, maka waktu baku akan dihitung.

Waktu baku $=$ waktu normal $\times(1+$ allowance $)$

Tingkat allowance yang diberikan dalam perhitungan waktu baku ditentukan melalui ILO 
Allowance Rating. ILO Allowance Rating dapat dilihat pada tabel 2 .

Tabel 2. ILO Allowance Rating

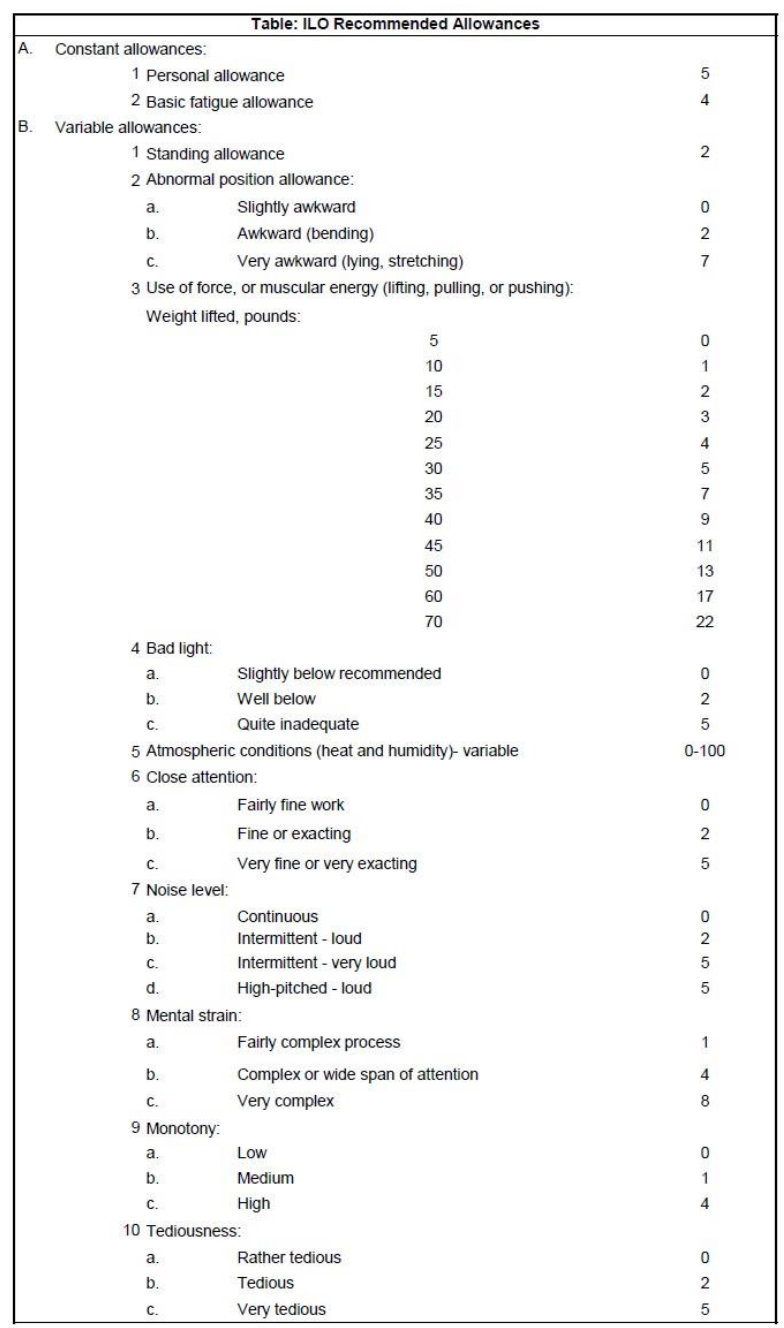

Melalui perhitungan yang dilakukan, waktu baku sebesar 17.1 detik, yang berarti kapasitas produksi per hari sebesar 77 bungkus.

Dalam pembuatan kembang goyang, dapat dilihat dan dirasakan bahwa terdapat perbedaan yang signifikan diantara satu kembang goyang dengan yang lain. Maka dari itu perbedaan kembang goyang dilakukan dengan tiga metode, yaitu melalui perbedaan visual secara sekilas, Texture Analyzer, dan Chroma Meter. Produk kembang goyang sebelum SOP dapat dilihat sebagai di Gambar 1.

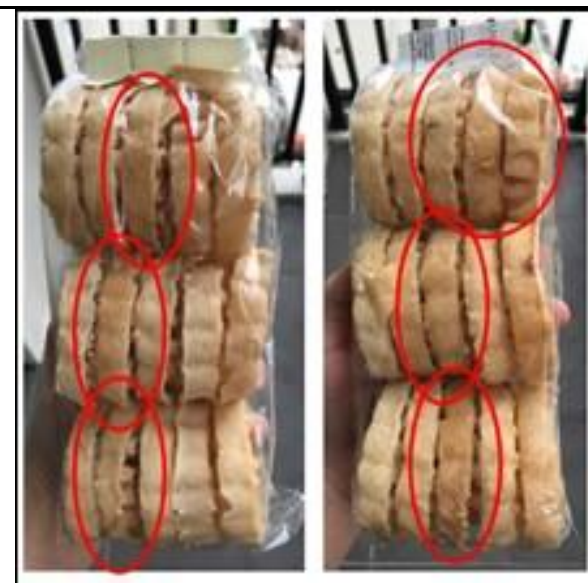

Gambar 1. Kembang goyang sebelum penerapan SOP

Pada Tabel 3 dapat dilihat data yang didapatkan melalui Texture Analyzer dan Chroma Meter.

Tabel 3. Data Texture Analyzer dan Chroma Meter

\begin{tabular}{|l|c|c|c|}
\hline \multicolumn{1}{|c|}{ Alat } & $\begin{array}{c}\text { Nilai Rata- } \\
\text { rata (g) }\end{array}$ & $\begin{array}{c}\text { Standar } \\
\text { Deviasi (g) }\end{array}$ & $\begin{array}{c}\text { Persentase } \\
\text { Standar } \\
\text { Deviasi }\end{array}$ \\
\hline $\begin{array}{l}\text { Texture } \\
\text { Analyzer }\end{array}$ & 8703.23 & 2071.42 & $23.8 \%$ \\
\hline $\begin{array}{l}\text { Chroma } \\
\text { Meter }\end{array}$ & 46.54 & 3.99 & $8.58 \%$ \\
\hline
\end{tabular}

Selama produksi kembang goyang, waktu yang digunakan untuk satu siklus produksi kembang goyang adalah 3485 detik. Proses produksi digambarkan melalui VSM. VSM produksi kembang goyang untuk proses produksi utama dapat dilihat pada Gambar 2. dan proses produksi parallel pemanasan minyak dapat dilihat pada Gambar 3.

Gambar 2. Proses produksi kembang goyang

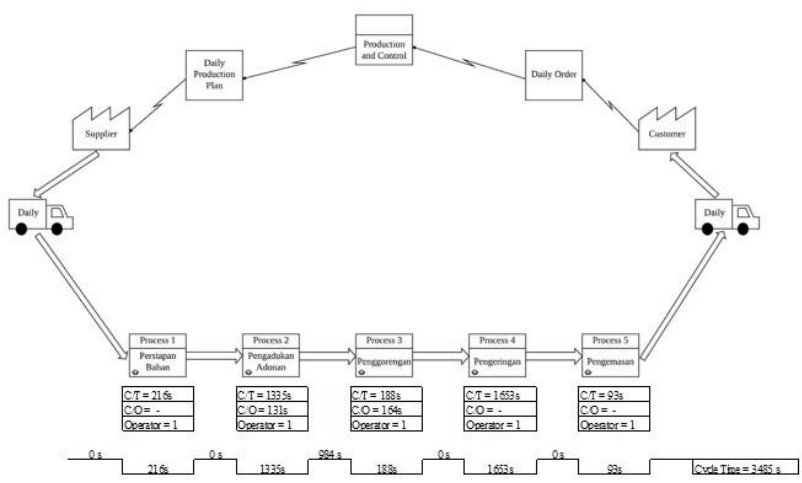




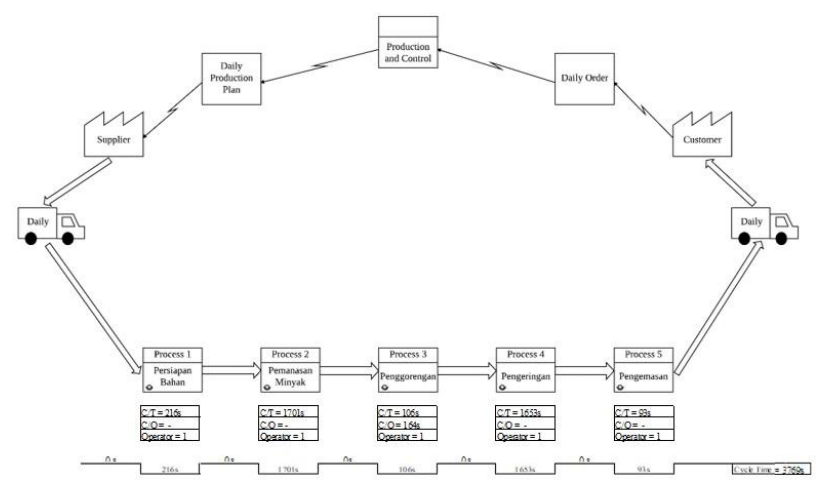

Gambar 3. Proses produksi parallel pemanasan minyak

\section{B. Proses penerapan SOP}

Dalam proses penerapan SOP, ditemukan bahwa proses yang paling berdampak adalah proses pengadukan adonan dan proses penggorengan. Untuk proses pengadukan adonan agar seluruh adonan yang digunakan lebih konsisten maka pada pengabdian kepada masyarakat ini diberikan mixer kepada UMKM Ibu Supiyah. Sebelum mixer diberikan, maka perlu dipastikan terlebih dahulu bahwa rumah Ibu Supiyah dapat memenuhi daya yang diperlukan. Setelah dilakukan perhitungan dapat diketahui bahwa daya listrik yang tersedia sebesar 1150 watt, total penggunaan listrik yang di rumah Ibu Supiyah adalah 247 watt. Dengan demikian, diketahui bahwa kapasitas daya yang masih tersedia sebesar 903 WattSelain itu, harus dipastikan juga bahwa mixer memiliki kemampuan yang cukup untuk mengaduk kembang goyang. Dengan semua pertimbangan yang ada, maka mixer yang diberikan kepada UMKM Ibu Supiyah adalah Bosch MUM44R1 Kitchen Mixer seperti pada gambar 4.

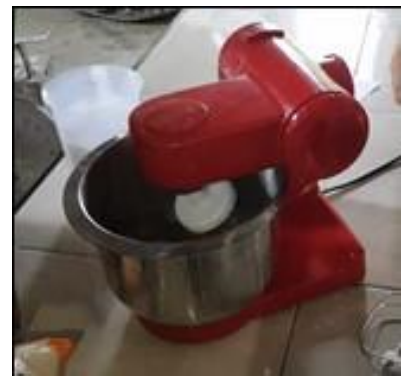

Gambar 4. Bosch MUM44R1 Kitchen Mixer
SOP yang diberikan kepada UMKM Ibu Supiyah dapat dilihat di Tabel 4.

Tabel 4. SOP Proses Pengadukan Adonan

\begin{tabular}{|c|c|c|c|c|}
\hline \multicolumn{5}{|c|}{ STANDAR OPERASI PROSEDUR } \\
\hline \multicolumn{5}{|c|}{ PEMBUATAN ADONAN } \\
\hline \multicolumn{5}{|c|}{ Tanggal dokumen: 24 Juli 2019} \\
\hline \multicolumn{5}{|c|}{ Penanggung jawab: Ibu Acan } \\
\hline & Nama & Posisi & TTD & Tanggal \\
\hline Pekerja & Ibu Acan & Pekerja & & \\
\hline Pemeriksa & - & & & \\
\hline Penugasan & UMKM Ibu Supiyah & & & \\
\hline Pembuat SOP & Franco Pratama & & & \\
\hline Penyetuju SOP & - & & & \\
\hline $\begin{array}{l}\text { Dokumen yang } \\
\text { terkait }\end{array}$ & \multicolumn{4}{|l|}{ - } \\
\hline $\begin{array}{l}\text { Peralatan yang } \\
\text { digunakan }\end{array}$ & \multicolumn{4}{|l|}{ Alat Mixer } \\
\hline Tujuan & \multicolumn{4}{|c|}{$\begin{array}{l}\text { Tujuan dari SOP pengadukan adonan adalah agar } \\
\text { adonan yang digunakan dalam seluruh lantai produksi } \\
\text { akan konsisten }\end{array}$} \\
\hline Tanggung Jawab & \multicolumn{4}{|c|}{$\begin{array}{l}\text { Bertanggung jawab untuk memproduksi kembang } \\
\text { goyang sesuai dengan permintaan pemilik UMKM. }\end{array}$} \\
\hline Definisi & \multicolumn{4}{|c|}{$\begin{array}{l}\text { Prosedur dibuat untuk menyediakan urutan proses } \\
\text { produksi agar proses pengadukan adonan lebih rapi dan } \\
\text { konsisten. }\end{array}$} \\
\hline \multicolumn{5}{|c|}{ Prosedur } \\
\hline Nomor Aktifitas & \multicolumn{4}{|c|}{ Aktifitas } \\
\hline 1 & \multicolumn{4}{|c|}{$\begin{array}{l}\text { Memasang mixer ke sumber listrik, dan menegakkan } \\
\text { mesin pengaduk menggunakan kepala adonan cair. }\end{array}$} \\
\hline 2 & \multicolumn{4}{|c|}{$\begin{array}{l}\text { Memasukkan bahan awal, yaitu telur, garam, gula, } \\
\text { paneli, santen tara, dan campuran air kapur ke dalam } \\
\text { wadah pengaduk. }\end{array}$} \\
\hline 3 & \multicolumn{4}{|c|}{$\begin{array}{l}\text { Menurunkan mesin pengaduk dan memutar pengatur } \\
\text { tenaga pengaduk ke } 2 \text { selama } 5 \text { menit. }\end{array}$} \\
\hline 4 & \multicolumn{4}{|c|}{$\begin{array}{c}\text { Setelah campuran awal sudah jadi, tegakkan kembali } \\
\text { mesin pengaduk, mengganti kepala adonan cair menjadi } \\
\text { kepala adonan keras dan masukkan tepung beras dan } \\
\text { tepung tapioca ke dalam wadah pengaduk. }\end{array}$} \\
\hline 5 & \multicolumn{4}{|c|}{$\begin{array}{c}\text { Turunkan mesin pengaduk dan memutar pengatur tenaga } \\
\text { ke } 2 \text { selama } 3 \text { menit sambil memasukkan air perlahan- } \\
\text { lahan. }\end{array}$} \\
\hline 6 & \multicolumn{4}{|c|}{$\begin{array}{c}\text { Setelah } 4 \text { menit sudah berlalu, tegakkan kembali } \\
\text { pengaduk adonan dan gantikan kepala adonan keras } \\
\text { menjadi kepala adonan cair. }\end{array}$} \\
\hline 7 & \multicolumn{4}{|c|}{$\begin{array}{l}\text { Memutar kembali pengatur tenaga ke } 2 \text { dan biarkan } \\
\text { mesin mengaduk selama } 4 \text { menit. }\end{array}$} \\
\hline 8 & \multicolumn{4}{|c|}{$\begin{array}{c}\text { Memindahkan adonan yang sudah diaduk ke dalam } \\
\text { wadah adonan. }\end{array}$} \\
\hline
\end{tabular}


Namun, karena pekerja di UMKM Ibu Supiyah masih belum terbiasa dengan format SOP yang formal, maka petunjuk diberikan dalam format IK (Instruksi Kerja). IK yang diberikan dapat dilihat dalam Gambar 5.

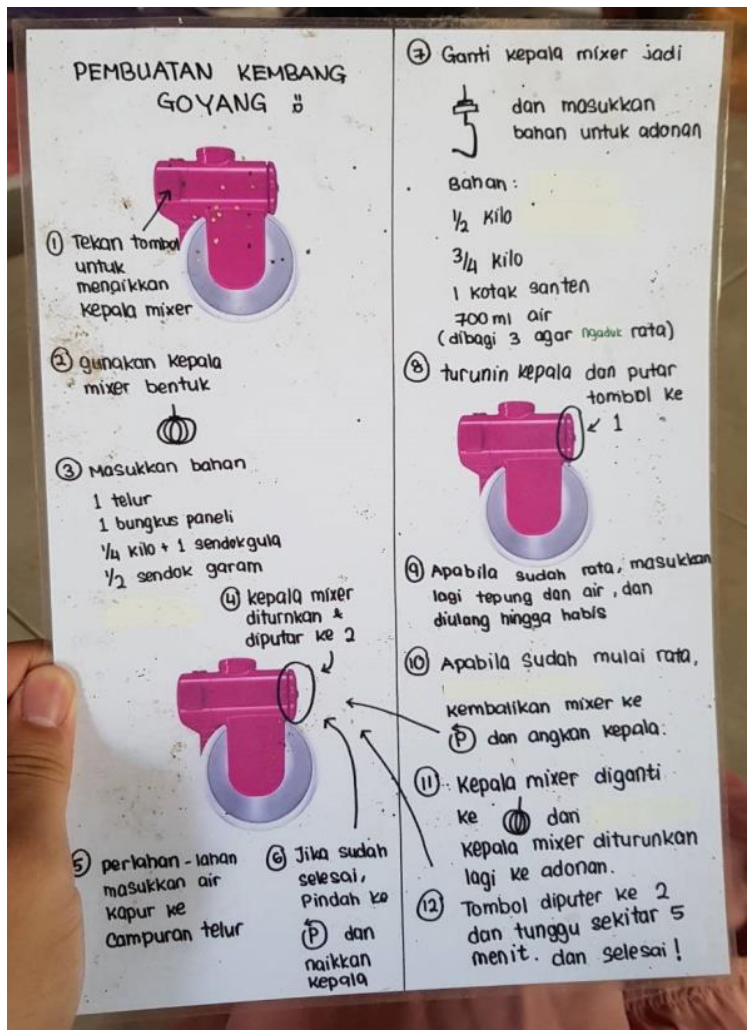

Gambar 5. Instruksi Kerja Pengunaan alat Mixer

Dalam proses penggorengan, ditemukan bahwa suhu yang digunakan untuk proses penggorengan tidak konsisten. Maka dari itu, diberikan thermometer minyak goreng. Thermometer dapat dilihat dalam Gambar 6.

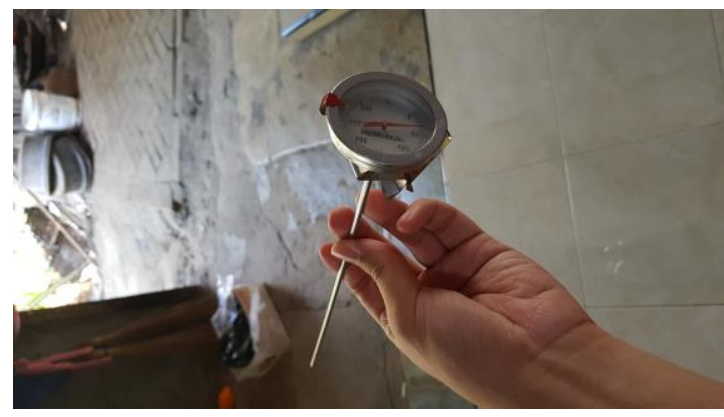

Gambar 6. Deep Fry Thermometer
SOP yang diberikan kepada UMKM Ibu Supiyah dapat dilihat di Tabel 5.

\section{Tabel 5. SOP Proses Penggorengan}

\begin{tabular}{|c|c|c|c|c|}
\hline \multicolumn{5}{|c|}{ STANDAR OPERASI PROSEDUR } \\
\hline \multicolumn{5}{|c|}{ PENGGORENGAN } \\
\hline \multicolumn{5}{|c|}{ Tanggal dokumen: 24 Juli 2019} \\
\hline \multicolumn{5}{|c|}{ Penanggung jawab: Ibu Acan } \\
\hline & Nama & Posisi & TTD & Tanggal \\
\hline Pekerja & Ibu Acan & Pekerja & & \\
\hline Pemeriksa & - & & & \\
\hline Penugasan & UMKM Ibu Supiyah & & & \\
\hline Pembuat SOP & Franco Pratama & & & \\
\hline Penyetuju SOP & - & & & \\
\hline $\begin{array}{l}\text { Dokumen yang } \\
\text { terkait }\end{array}$ & \multicolumn{4}{|l|}{-} \\
\hline $\begin{array}{l}\text { Peralatan yang } \\
\text { digunakan }\end{array}$ & \multicolumn{4}{|c|}{ Wok, kompor, alat cetak, thermometer, wadah adonan } \\
\hline Tujuan & \multicolumn{4}{|c|}{$\begin{array}{l}\text { Tujuan dari SOP penggorengan adalah agar kembang } \\
\text { goyang yang diproduksi di lini produksi yang berbeda } \\
\text { akan memiliki warna dan kegurihan yang konsisten. }\end{array}$} \\
\hline Tanggung Jawab & \multicolumn{4}{|c|}{$\begin{array}{l}\text { Bertanggung jawab untuk memproduksi kembang } \\
\text { goyang sesuai dengan permintaan pemilik UMKM. }\end{array}$} \\
\hline Definisi & \multicolumn{4}{|c|}{$\begin{array}{l}\text { Prosedur dibuat untuk menyediakan urutan proses } \\
\text { produksi agar proses penggorengan lebih rapi dan } \\
\text { konsisten. }\end{array}$} \\
\hline $\begin{array}{l}\text { Indikator } \\
\text { Keberhasilan }\end{array}$ & \multicolumn{4}{|c|}{$\begin{array}{l}\text { Kembang goyang yang } \mathrm{d} \\
\text { konsisten. }\end{array}$} \\
\hline \multicolumn{5}{|c|}{ Prosedur } \\
\hline Nomor Aktifitas & \multicolumn{4}{|c|}{ Aktifitas } \\
\hline 1 & \multicolumn{4}{|c|}{ Mempersiapkan stasiun penggorengan } \\
\hline 2 & \multicolumn{4}{|c|}{ Memanaskan minyak goreng hingga $200^{\circ} \mathrm{C}$} \\
\hline 3 & \multicolumn{4}{|c|}{$\begin{array}{l}\text { Memasukkan alat cetak kembang goyang ke dalam } \\
\text { minyak selama menunggu minyak mencapai suhu yang } \\
\text { diinginkan. }\end{array}$} \\
\hline 4 & \multicolumn{4}{|c|}{$\begin{array}{l}\text { Memasukkan cetakkan ke wadah adonan, dan } \\
\text { dipindahkan ke minyak goreng. }\end{array}$} \\
\hline 5 & \multicolumn{4}{|c|}{$\begin{array}{l}\text { Memperhatikan warna kembang goyang hingga berubah } \\
\text { menjadi coklat pucat. }\end{array}$} \\
\hline 6 & \multicolumn{4}{|c|}{$\begin{array}{l}\text { Memutar kembang goyang agar bagian muka dari } \\
\text { kembang goyang menghadap keatas. }\end{array}$} \\
\hline 7 & \multicolumn{4}{|c|}{$\begin{array}{l}\text { Mengambil kembang goyang yang sudah bewarna } \\
\text { kecoklatan. }\end{array}$} \\
\hline 8 & \multicolumn{4}{|c|}{ Memasukkan kembang goyang ke wadah pengeringan. } \\
\hline 9 & \multicolumn{4}{|c|}{$\begin{array}{l}\text { Memastikan bahwa suhu minyak berada diantara } 190^{\circ} \mathrm{C} \\
\text { dan } 210^{\circ} \mathrm{C} \text {. }\end{array}$} \\
\hline 10 & \multicolumn{4}{|c|}{$\begin{array}{l}\text { Melakukan inspeksi untuk memastikan bahwa warna } \\
\text { kembang goyang yang dihasilkan konsisten. }\end{array}$} \\
\hline
\end{tabular}

\section{Setelah Penerapan SOP}

Setelah SOP sudah diterapkan, kembang goyang akan diuji dan dibandingkan lagi dengan pengujian sebelomnya. Pengujian akan dilakukan dua kali pengulangan. Secara visual, kembang goyang dapat dilihat di Gambar 7. dan Gambar 8.

Teknologi Tepat Guna 


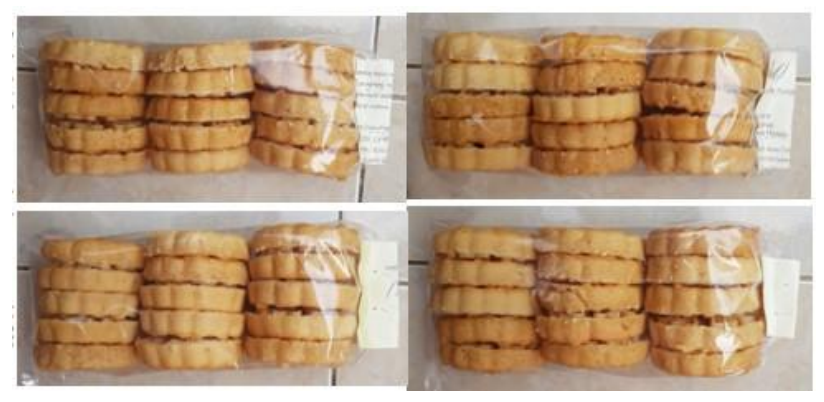

Gambar 7. Pengujian visual pertama Gambar 8. Pengujian visual kedua

Kembang goyang juga kemudian diuji menggunakan Texture Analyzer dan Chroma Meter lagi. Data Texture Analyzer dan Chroma Meter dapat dilihat di Tabel 6.

Tabel 6. Data Texture Analyzer dan Chroma Meter setelah penerapan SOP

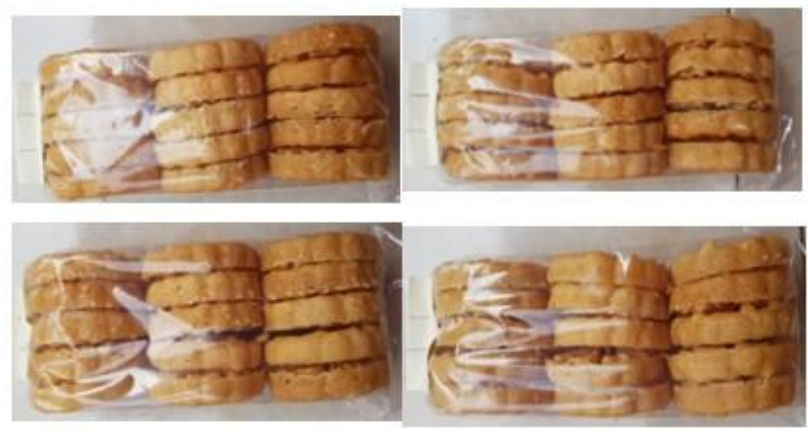

\begin{tabular}{|l|c|c|c|}
\hline \multicolumn{1}{|c|}{ Alat } & $\begin{array}{c}\text { Nilai Rata- } \\
\text { rata (g) }\end{array}$ & $\begin{array}{c}\text { Standar } \\
\text { Deviasi (g) }\end{array}$ & $\begin{array}{c}\text { Persentase } \\
\text { Standar } \\
\text { Deviasi }\end{array}$ \\
\hline $\begin{array}{l}\text { Texture } \\
\text { Analyzer (I) }\end{array}$ & 7846.4 & 1157.76 & $14.8 \%$ \\
\hline $\begin{array}{l}\text { Chroma } \\
\text { Meter }\end{array}$ & 40.86 & 3.2 .87 & $7.02 \%$ \\
\hline $\begin{array}{l}\text { Texture } \\
\text { Analyzer (II) }\end{array}$ & 7846.4 & 1157.76 & $15.60 \%$ \\
\hline
\end{tabular}

Setelah semua SOP sudah diterapkan, maka waktu yang digunakan untuk produksi juga berubah. VSM baru yang dihasilkan setelah SOP diterapkan dapat dilihat di Gambar 9. dan Gambar 10.
Gambar 9. VSM setelah penerapan SOP

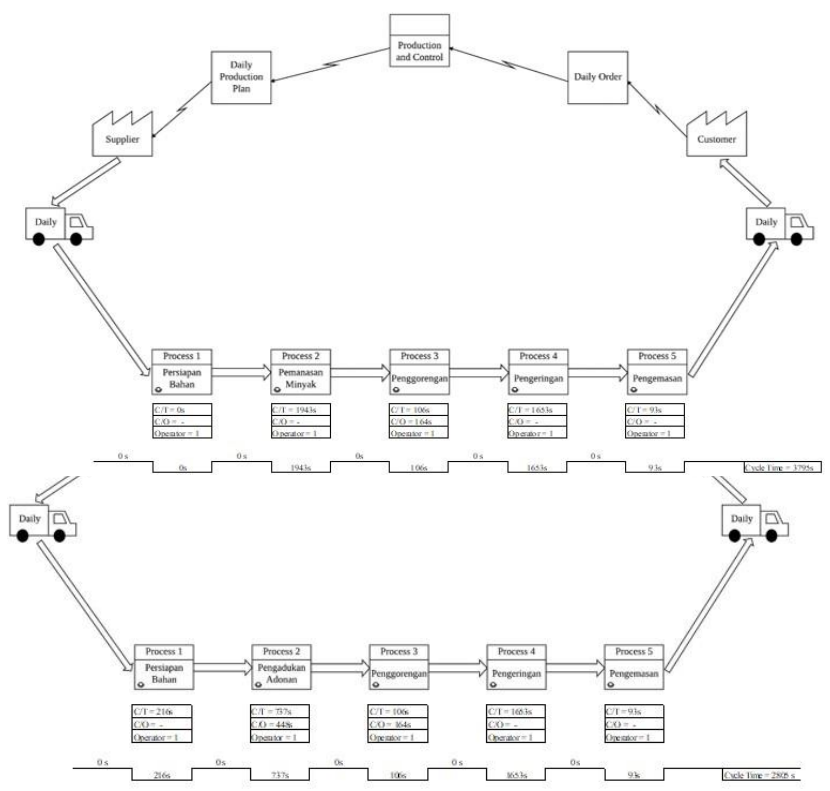

Gambar 10. VSM parallel pemanasan minyak setelah penerapan SOP

Melalui perbandingan data sebelum dan setelah SOP diterapkan, dapat dilihat bahwa secara tekstur, tingkat hardness memiliki persentase ratarata sebesar $15,2 \%$, dimana sebelumnya, tingkat standar deviasi sebesar 23,8\%. Hal ini menunjukkan bahwa persentase hardness berkurang sebesar $8,6 \%$. Diketahui juga bahwa persentase standar deviasi menurun dari $8,58 \%$ hingga $7,02 \%$, yaitu sebesar $1,51 \%$.

Hal ini menunjukkan bahwa penerapan SOP dalam tahap pengadukan adonan dan penggorengan memiliki dampak kepada tingkat konsistensi proses produksi kembang goyang. Maka dari itu, dapat disimpulkan bahwa pengunaan mesin mixer dalam pembuatan adonan dan menetapkan suhu dan metode penggorengan dalam tahap penggorengan dapat meningkatkan tingkat konsistensi kembang goyang. 


\section{KESIMPULAN}

Sebelum SOP diterapkan, diketahui bahwa faktor yang menyebabkan berbedanya warna dan tingkat kegurihan dari produk kembang goyang adalah akibat proses pengadukan dan penggorengan yang tidak konsisten sehingga perlu dIbuat SOP. Berdasarkan hasil pengujian setelah SOP diterapkan, tingkat konsistensi warna dan kegurihan dalam produksi kembang goyang meningkat sehingga dapat menjamin standar kualitas produk. Dapat dikatakan bahwa dengan konsistennya warna dan tingkat kegurihan kembang goyang maka kualitas produk menjadi lebih baik. Demikian juga dengan waktu siklus proses produksi kembang goyang juga berkurang sebesar 680 detik. Dapat disimpulkan bahwa tujuan pengabdian kepada masyarakat telah tercapai.

Dengan telah selesai dan tercapainya tujuan dari PKM ini maka direkomendasikan agar UMKM Ibu Supiyah dapat menerapkan SOP yang telah dibuat dengan menggunakan alat baru yang diberikan yaitu Bosch MUM44R1 Kitchen Mixer untuk proses pembuatan adonan agar hasil adonan tetap konsisten serta menggunakan Deep Fry Thermometer agar dapat mengukur dan mengatur suhu dari minyak goreng tetap stabil sehingga diharapkan produk kembang goyang dapat konsisten kegurihan dan warnanya.

\section{UCAPAN TERIMAKASIH}

Terimakasih kepada Lembaga Penelitian dan Pengabdian Kepada Masyarakat Universitas peli Harapan yang telah mendukung dan mendanai PKM ini.

\section{REFERENSI}

A. Gede Ajusta, Syahrial Addin. 2018. "Analisis Penerapan Standar Operasional Prosedur (SOP) Di Departemen HRD PT Sumber Maniko Utama." Mitra Manajemen (JJM Online) 2 (1):181-89.

Atmoko, Tjipto. Standar Operasional Prosedur (SOP) dan Akuntabilitas Kinerja Instansi Pemerintah. Jakarta: Skripsi Unpad, 2012. Retrieved https://docplayer.info/430513-Standar- operasional-prosedur-sop-dan-akuntabilitaskinerja-instansi-pemerintah-tjiptoatmoko.html

Badan Pusat Statistika. Indeks produksi triwulan industri makro dan kecil $(2010=100)$ menurut 2-digit KBLI, 2011-2019 https://www.bps.go.id/dynamictable/2015/1 1/04/974/indeks-produksi-triwulananindustri-mikro-dan-kecil-2010-100menurut-2-digit-kbli-20112018.html:internet diakses 3 Juli 2019

Bank Indonesia dan LPPI. 2015. "Profil Bisnis Usaha Mikro, Kecil Dan Menengah (UMKM)," 149.

Bundalo, Dušanka, Ferid Softi Ć, and Branimir Cviji Ć. 2016. "ANNALS of Faculty Engineering Hunedoara - International Journal of Engineering ENVIRONMENTAL DATA MONITORING USING WIRELESS," 99103.

Barnes, Ralph M. Motion and Time Study Design and Measurement of Work. John Wiley and Sons, 1980.

Dinata, Kenni Dian. 2018. "Operasional dan Pengendalian Mutu pada Proses Produksi Sandal Home Industry."

Dunford, Nurhan. 2003. "Deep-Fat Frying Basics for Food Services Fryer, Oil and Frying Temperature Selection." Fapc.Okstate.Edu. http://pods.dasnr.okstate.edu/docushare/dsw eb/Get/Version-3803/FAPC-126web.pdf.

Forno, Ana Julia Dal, Fernando Augusto Pereira, Fernando Antonio Forcellini, and Liane M. Kipper. 2014. "Value Stream Mapping: A Study about the Problems and Challenges Found in the Literature from the Past 15 Years about Application of Lean Tools." International Journal of Advanced Manufacturing Technology 72 (5-8):77990. https://doi.org/10.1007/s00170-0145712-z.

Gunawan, Binta. 2014. "Proses Pemberdayaan Usaha Kecil Menengah Melalui Penerapan Teknologi Tepat Guna," 203.

Heliantina, Farah. 2017. Siaran Pers - Ekonomi Digital Mempercepat Pembangunan Ekonomi. Kementerian Koordinator Bidang Perekonomian Republik Indonesia. Tersedia di www.ekon.go.id

$$
\text { Teknologi Tepat Guna }
$$


Hyslop, Nicole Pauly, and Warren H. White. 2009. "Estimating Precision Using Duplicate Measurements." Journal of the Air and Waste Management Association 59 (9):1032-39. https://doi.org/10.3155/10473289.59.9.1032.

Permata, Lusia, and Sari Hartanti. 2016. "Work Measurement Approach To Determine Standard Time in Assembly Line." Nternational Journal of Management and Applied Science 2.1 (August):49-52.

Rikasari, Fauzia, Program Studi, and Informasi Perpustakaan. n.d. 2017. "Pembuatan
Standard Operating Procedure ( SOP ) Arsip Dinamis Aktif Di Unit Procurement \& Logistic Staff, Proyek Indarung Vi Pt Semen Padang."

Ríos, Coronado, Alejandro Ivan, Romandia Castro, Hector Ernesto, Ramirez Careaga, Rodriguez Rivera, Nora Helena, De la vega Bustillos, and b Enrique. 2015. "Determination of Allowances for Standard Time." 19th Triennial Congress of the International Ergonomics Association, 1672. 